\title{
Effects of alkali-silica reaction on a hydropower structure after 50 years of ongoing deterioration
}

\author{
Rene Brueckner ${ }^{1}$, Noah Ndugga ${ }^{2}$, and Tony C. Meri ${ }^{2}$ \\ ${ }^{1}$ Mott MacDonald, Bristol, United Kingdom \\ ${ }^{2}$ Mott MacDonald, Kampala, Uganda
}

\begin{abstract}
The Nalubaale hydropower station was constructed between 1949 and 1954 . Deterioration of the powerhouse structure was first noticed in 1964 when hairline cracking in the generator floor started to appear. The cracking progressively continued resulting in degradation of the generator floor, upper gallery and structural frame of the powerhouse. It was not until 1990 that alkali-silica reaction (ASR) in the mass concrete elements was identified to be the root cause of the deterioration. The condition of the powerhouse structure was reassessed in 201525 years after the investigations in 1990. The assessment comprised the determination of the concrete properties 50 years after ASR had initiated and a comprehensive evaluation of instrumentation data was undertaken to identify the effects of ASR on the powerhouse structure. This paper presents the findings of the condition assessment and provides an update on the concrete properties after more than 50 years of ongoing ASR. It also provides an assessment of the residual life of the structure and proposes rehabilitation methods to control the effects of ASR.
\end{abstract}

\section{Introduction}

The hydropower station, known as Nalubaale, is located near Jinja along the River Nile a few kilometres downstream of Lake Victoria and approximately $80 \mathrm{~km}$ east of the Ugandan capital, Kampala. The power station complex comprises a concrete arch gravity dam, concrete gravity intake structure and the powerhouse. The dam has a maximum height of approximately $30 \mathrm{~m}$ and a crest length of $726 \mathrm{~m}$ whereas the intake structure, which is separated by high ground from the main dam, is $25 \mathrm{~m}$ high with a crest length of $160 \mathrm{~m}$. The powerhouse, $167.6 \mathrm{~m}$ long and $16.5 \mathrm{~m}$ wide, is monolithically joined to the intake structure at the base and houses 10 No. turbines and generators with a total current capacity of 180 MW. Figure 1 shows a cross-section of the intake and powerhouse.

The power station was constructed between 1949 and 1954 when the first two units were commissioned and the plant was known as Owen Falls. The remaining 8 No. units followed in the period until 1968 to provide an original generating capacity of $150 \mathrm{MW}$, later upgraded to $180 \mathrm{MW}$ at the beginning of the 1990 s during major refurbishment works. Until the 1990s the plant exported power to East Africa in addition to covering the national electricity demand. Nowadays the plant provides lowcost electricity counteracting the more expensive power provided by the recently commissioned hydropower stations.

\section{Deterioration of the powerhouse}

The expected service life of the hydropower plant has been significantly affected by the deterioration of the powerhouse. The design life of the dam and civil elements of the plant was intended to be up to 100 years; however, alkali-silica reaction has caused significant deterioration of the structure which has also affected the performance and service life of the mechanical equipment.

Deterioration of the powerhouse structure was first noticed in 1964 when hairline cracking of concrete started to appear around the generator housing of Unit \#4 [1]. In 1977 it became apparent that the concrete cracking had continued, resulting in a pronounced crack pattern in the generator floor and upper gallery. A more detailed inspection in 1983 revealed cracks up to $25 \mathrm{~mm}$ wide through the generator floor and running the length of the powerhouse. The cracking at Unit \#4 had increased significantly and was mirrored at all other units.

In 1984/85 concrete core samples were retrieved at selected locations in the powerhouse and petrographically examined. The examination did not show any signs of alkali-aggregate reaction. The root cause was considered to be the instability of the spirals due to lack of reinforcement, which is aggravated in turn by high pressures within the draft tube. Based on these conclusions, it was recommended that the spirals should be post-tensioned to reinforce the unreinforced mass concrete elements. Post-tensioning anchors were then

* Corresponding author: rene.brueckner@mottmac.com 
installed from 1989 to 1991 during major refurbishment works. Selected post-tensioning anchors have been monitored since 1995 when load cells were installed at 6 out of a total of 115 No. vertical and inclined anchors [2].

After installation of the first post-tensioning anchors in 1990 it became apparent that the post-tensioning did not seem to be preventing ongoing deterioration as a result of the assumed root cause which was simple structural overload, spiral instability, and further investigations were required [1]. The investigation identified that in addition to the cracking, vertical movement of the generator floor and downstream deflection of the structural frame were also present. The downstream movement affected the crane rail requiring an adjustment of $9.5 \mathrm{~mm}$.

The investigation concluded that alkali-aggregate reaction, specifically alkali-silica reaction, had been the root cause of the structural deterioration. The observations and measurements showed that a downstream movement of $1 \mathrm{~mm} /$ year at generator floor level had taken place with a total measured displacement of $32 \mathrm{~mm}$. The vertical displacement at generator floor level was found to be $76 \mathrm{~mm}$.

2D modelling of the deterioration predicted in 1990 a total displacement of $62 \mathrm{~mm}$ and $150 \mathrm{~mm}$ in horizontal and vertical direction, respectively, for the year 2020 [3].

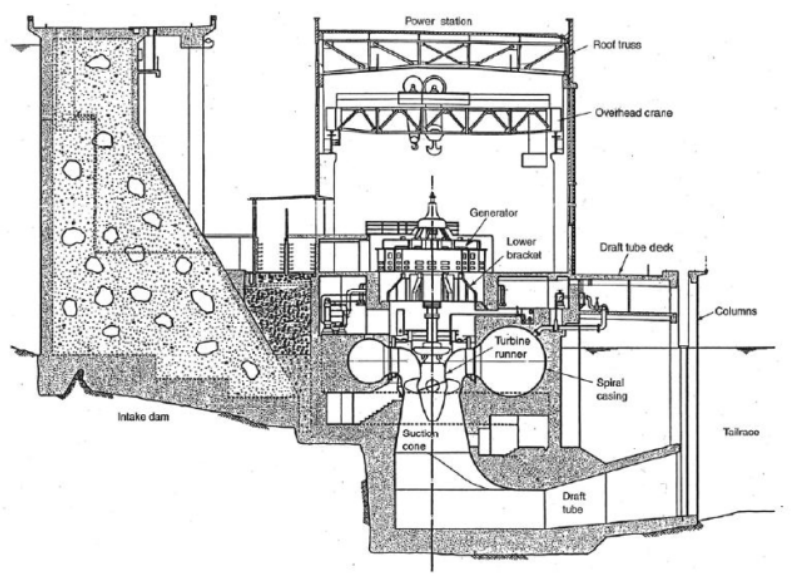

Fig. 1. Powerhouse section

\section{Alkali-aggregate reaction}

Alkali-aggregate reaction has previously been distinguished into three types: alkali-silica reaction (ASR), alkali-carbonate reaction (ACR) and alkalisilicate reaction. The latter is now recognised as a particular (slow/late) form of ASR and there is also debate that ACR is another different variation of ASR. Therefore, 'alkali-aggregate reaction' may actually only be alkali-silica reaction with various forms [4].

ASR is a chemical reaction between various forms of reactive silica, i.e. disordered, stressed or poorly crystalline silica within the aggregate, and alkali hydroxides $(\mathrm{NaOH}, \mathrm{KOH})$ from the pore solution in the presence of moisture. The alkalis mainly derive from the cement but can also be supplied from the aggregate itself and from external sources. The reaction product, the alkali-silica gel, is more voluminous than the concrete and, after exceeding the tensile strength of the concrete, generally forms a distinctive crack pattern. The cracks usually have the appearance of a spider web; however, affected prestressed elements tend to show cracks parallel to the stress direction.

The reaction can proceed when further water ingress takes place as the alkali-silica gel is able to react with water and calcium hydroxide to form calcium silicate hydrates and alkali hydroxides, which can form more gel and degrade concrete over a long term. This reaction is however a finite process because the majority of the alkalis remain in the gel, but it is difficult to estimate the time when the reaction may cease, if at all. As moisture is required in the reaction the rate of ASR may reduce when the relative humidity in the concrete decreases towards the region of 75 to $80 \%$ [5]. The formation of the alkali-silica gel causes swelling and the expansion pressure developed during this process can reach up to $20 \mathrm{~N} / \mathrm{mm}^{2}$, exceeding the tensile strength of concrete, which is in the range of 2-5 N/mm 2 [6].

The ASR reaction affects the appearance and serviceability of a structure, although generally its structural integrity, particularly the compressive strength, is not significantly affected. However, the formation of cracks can enhance the penetration of various aggressive compounds, leading to acceleration of other types of degradation. ASR is often observed in combination with corrosion and sulphate attack and can be their predecessor.

In the case of confirmed ASR degradation in structural elements, there are a series of measures to monitor and control ASR. The IStructE Report $62-$ 'Structural effects of alkali-silica reaction: technical guidance on appraisal of existing structures' describes these measures as follows [7]:

- Regular monitoring of the structure to check that deterioration does not reach dangerous proportions. This requires experienced engineering judgment.

- Detailed check on the structural details to establish criticality, in particular, a critical examination of the robustness of the reinforcement detailing.

- Measures to reduce the amount of water available to the structure.

- Limited strengthening of the structure.

- Partial or full demolition followed by rebuilding.

The appropriate measure should be assessed through investigations comprising the documentation of the degradation, a desk study to gain information about the materials used, the type of construction, and the rate of degradation. Destructive investigations should include the retrieval of cores in degraded and sound areas for assessment and comparison in the laboratory. This may include compressive strength and E-Modulus (Young's Modulus) tests, petrographic examination, expansion testing and visual inspection. 


\section{Powerhouse condition in 1990}

The 1984/85 root cause analysis [3] was not able to confirm the presence of ASR following visual inspections and using petrographic analysis of core samples. The petrographic analysis identified the fine and coarse aggregate as siliceous sand and amphibolite coarse aggregate, respectively, which were classified as non-reactive.

The characteristic map cracking that is normally associated with ASR has generally been absent and no movements or cracks were noticed for the first 10 years of the powerhouse's life. Other observations that did not support ASR as a cause is that the movements were variable with Units \#1 and \#2 being hardly affected, whereas the generator floor level rose up to $75 \mathrm{~mm}$ between Units \#5 to \#9 in 1990. It was suggested that this high expansive strain is not common for ASR.

Following the progressive deterioration of the powerhouse structure and its contradictory deterioration patterns a more detailed investigation was undertaken by the designers of the plant in 1990 [3]. The investigation comprised a comprehensive review of available information from construction and previous inspections and more detailed materials testing. The testing included petrographic examination and determination of the concrete alkali-content, compressive strength and EModulus.

The document review revealed that the cement was obtained from two manufacturers. A low heat Portland cement from the UK had mainly been used in the concrete of the structural frame (Stage 1) of the powerhouse up to early 1953 . This cement was then replaced with a local Ugandan cement to construct the mass concrete elements (Stage 2) around the units and during the remaining works of the project, see Figure 2. The change was initiated by the opening of an Ugandan cement plant and the aim to reduce costs. Due to a transition period in the first half of 1953 when both cements were used, a clear cut-off point between the two cements and associated concrete elements was not possible to identify but was thought to be between Units \#1 and \#3.

The petrographic examination clearly identified the presence of alkali-silica reaction in the concrete core samples. Additionally, the analysis identified that the coarse aggregate is amphibole schist and not amphibolite as stated in 1984/85. Amphibole schist is a reactive aggregate in the presence of sufficient alkalis. There was no evidence that the fine aggregate contributed to the reaction. The degree of damage observed in the samples due to ASR was assessed to be moderate.

The alkali content of the Ugandan cement concrete was found to be ranging from 6.5 to $8.4 \mathrm{~kg} \mathrm{Na} 2 \mathrm{O} \mathrm{eq} / \mathrm{m}^{3}$ averaging $7.5 \mathrm{~kg} \mathrm{Na} \mathrm{Na}_{2} \mathrm{O} \mathrm{eq} / \mathrm{m}^{3}$ which corresponded to more than 3 times the limit specified by current standards. The alkali content of the cement was analysed to be $2.5 \% \mathrm{Na}_{2} \mathrm{O}$ eq. For comparison Portland cements (CEM I) to BS EN 197-1 currently produced in the UK generally range in their mean alkali-contents from about $0.4 \%$ to $0.7 \% \mathrm{Na}_{2} \mathrm{O}$ eq according to BRE Digest 330 .
The strain within the reactive concrete was assessed to be between 1 and $2 \mathrm{~mm} / \mathrm{m}$ which was considered to be significant but not severe. The rise in generator floor level of up to $75 \mathrm{~mm}$ between Units \#5 and \#9 was considered to be aggravated by the restraint condition of the mass concrete elements. The mass concrete is partially restrained and the only unrestrained expansion directions are vertically upwards and, to some extent, downstream. The concrete is fully restrained along the longitudinal axis of the powerhouse except Unit \#10.

The in-situ cube compressive strength was stated to be about $36 \mathrm{~N} / \mathrm{mm}^{2}$ and it was suggested that there was a reduction in strength over that expected for concrete of this mix design. In addition, a reduction of the EModulus as a result of ASR was clearly identified. The E-Modulus of ASR affected concrete was determined to be approx. $2 / 3$ of the unaffected concrete which was determined by using control samples. The static modulus of the control samples was $37,500 \mathrm{~N} / \mathrm{mm}^{2}$ [3].

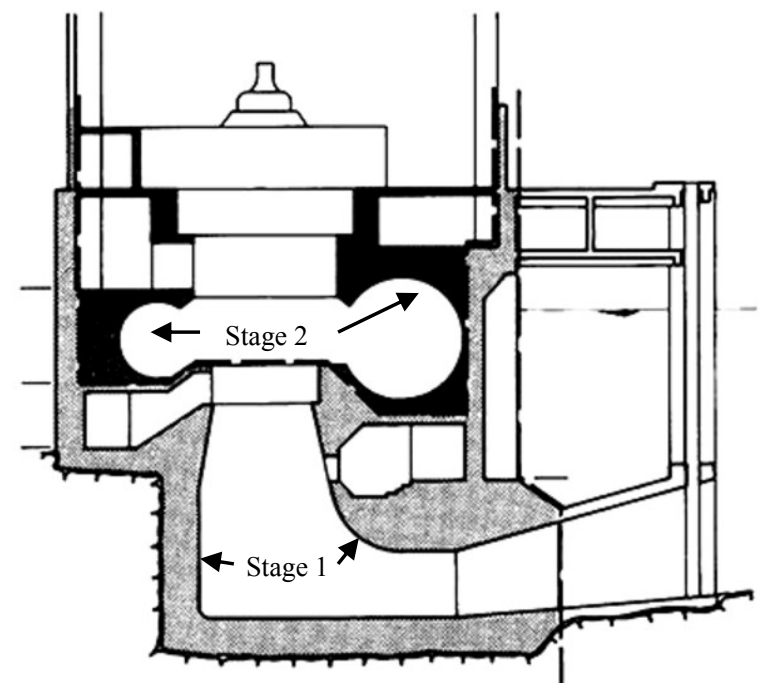

Fig. 2. Location of Stage 1 and Stage concrete [3]

\section{Effects on materials properties, 2015}

The condition of the powerhouse was re-assessed in 2015 with the objective to determine the effects of ASR on the structural integrity of the powerhouse and particularly on the materials properties after 50 years of visual deterioration from the onset of hairline cracking in 1964. The concrete properties were determined using similar investigation methods as in 1990. The testing comprised petrographic examination, compressive strength testing, determination of the static E-Modulus and alkali content of core samples retrieved from representative locations from the Stage 1 and Stage 2 concrete elements. Concrete core expansion tests were included to assess the potential and rate of future deterioration. The integrity of the powerhouse structural frame and roof structure was assessed using the available powerhouse monitoring data and by undertaking additional surveys.

The visual effects comprised longitudinal cracking of the generator floor as a result of the floor being pulled apart, diagonal cracking of the transverse walls of the 
turbine pits and alternator blocks in the upper gallery (see Figure 3) and horizontal transverse cracking of the draft tube walls indicating shear failure.

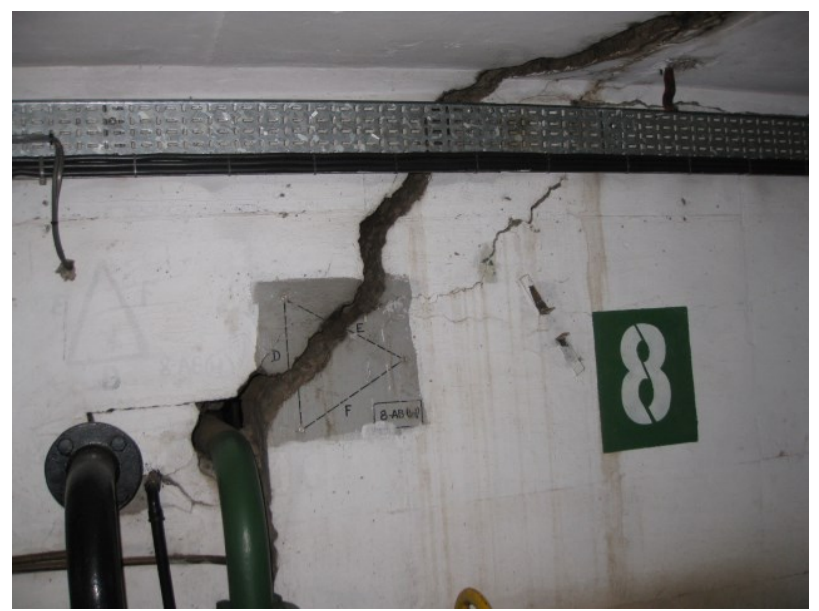

Fig. 3. Turbine pit wall

\subsection{Petrographic examination}

Petrographic analysis was carried out on 5 No. concrete core samples in accordance with the guidance of the 'Applied Petrography Group' [8] and ASTM C856-14 with samples retrieved from the powerhouse, intake and main dam. Cores within the powerhouse were retrieved from Stage 1 and Stage 2 concrete elements that were expected to be either fully saturated or moderately saturated.

The examination confirmed the presence of alkalisilica reaction in Stage 2 concrete where local cement was used. The relative severity of the reaction was assessed to be moderate to high and the gel deposits were generally found to be non-calcified, indicating ongoing reaction with a low probability of alteration. One core sample from an expected highly saturated element showed gel that was both calcified and noncalcified, suggesting that the reaction has partially ceased. ASR was also identified in a core sample where UK cement was expected, but it was not possible to confirm the cement using historic records.

The vertical cores from the Stage 2 mass concrete elements were mainly affected by horizontal surface parallel cracking, which indicates free vertical movement and horizontal restraint provided by the alternator blocks. The cores obtained from the downstream side of the powerhouse were more affected than those from the upstream side, confirming the 1990 observations.

The coarse aggregate was identified to be greenschist with small amounts of amphibolite. The fine fraction of the aggregate contained medium siliceous sand and minor quantities of crushed greenschist and amphibolite particles. Both fractions contained rock types that are potentially reactive with alkalis in cement paste but ASR was mainly associated with the coarse greenschist aggregate particles. The majority of the fine aggregate did not contribute to the degradation.
Based on the petrographic examination the original water-cement ratio ranged from 0.45 to 0.6 with a mean value of 0.5 . The cement was confirmed to be Ordinary Portland cement (OPC) with an average content of 385 $\mathrm{kg} / \mathrm{m}^{3}+/-50 \mathrm{~kg} / \mathrm{m}^{3}$. The findings confirmed the 1990 petrographic analysis results where the water-cement ratio was estimated to range from 0.52 to 0.6 and the average cement content was $350 \mathrm{~kg} / \mathrm{m}^{3}+/-50 \mathrm{~kg} / \mathrm{m}^{3}$ [3].

\subsection{Concrete compressive strength}

The in-situ concrete compressive strength was found to range from 23.5 to $54.5 \mathrm{~N} / \mathrm{mm}^{2}$ for Stage $1 \& 2$ concrete elements with an average in-situ cube strength of 36 $\mathrm{N} / \mathrm{mm}^{2}$ based on core samples. The Stage 1 concrete samples had a slightly higher compressive strength but no significant difference could be determined.

The in-situ compressive strength reported in 1990, that was based on cores, was $36 \mathrm{~N} / \mathrm{mm}^{2}$ with a range of 24 to $47 \mathrm{~N} / \mathrm{mm}^{2}$ which agrees with the 2015 findings. The characteristic cube compressive strength was determined in accordance with BS EN 13791 and found to be $31.5 \mathrm{~N} / \mathrm{mm}^{2}$ (2015) and $28.0 \mathrm{~N} / \mathrm{mm}^{2}$ (1990). The minimum strength of $24 \mathrm{~N} / \mathrm{mm}^{2}$ appears to be low based on the cement content and water-cement ratio identified during the petrographic examination.

The results indicate that the compressive strength does not appear to have deteriorated during the past 25 years. The effects of ASR on the compressive strength of concrete is generally considered to be low [9].

\subsection{Static Modulus of Elasticity}

The Modulus of Elasticity was determined in accordance with BS EN 12390-13 and found to range from 10,500 to $21,500 \mathrm{~N} / \mathrm{mm}^{2}$ with the majority of results from 5 No. cores in the region of 10,500 to $15,000 \mathrm{~N} / \mathrm{mm}^{2}$. The Concrete Society UK [10] states that the expected EModulus of a $\mathrm{C} 25 / 30$ concrete is approximately 31,000 $\mathrm{N} / \mathrm{mm}^{2}$ and of a $\mathrm{C} 30 / 37$ approximately $32,000 \mathrm{~N} / \mathrm{mm}^{2}$. The 1990 investigation reported an average E-Modulus of $22,100 \mathrm{~N} / \mathrm{mm}^{2}$ with a minimum value of 16,100 $\mathrm{N} / \mathrm{mm}^{2}$ (Unit \#4) and maximum value of $28,100 \mathrm{~N} / \mathrm{mm}^{2}$ (Unit \#3). The control value reported for the identified mix design was $37,000 \mathrm{~N} / \mathrm{mm}^{2}$ [3].

The E-Modulus was reported to have reduced to two thirds of the expected original E-Modulus of the concrete based on the 1990's control value and the 2015 results show that it has further deteriorated to approximately one third. These correspond with $30 \%$ and $35 \%$ of the 1990 control value and the expected E-Modulus stated by the Concrete Society [10], respectively. The reduction of the E-Modulus was apparent in both Stage 1 and Stage 2 concrete. The cracks resulting from ASR significantly affect the E-Modulus of concrete and the results indicate a virtual linear deterioration since commencement of the reaction when cracking was first observed in 1964. 


\subsection{Alkali content}

The alkali content of both Stage 1 and Stage 2 concrete was determined in accordance with BS 1881-124 and appeared to be significantly higher than the results reported in 1990. The $\mathrm{Na}_{2} \mathrm{O}$ equivalent of the concrete was found to range from 8.9 to $28 \mathrm{~kg} / \mathrm{m}^{3}$, which is unrealistically high and therefore unrepresentative. However, cement may contain 0.1 to $1.5 \% \mathrm{~K}_{2} \mathrm{O}$ and 0.1 to $0.8 \mathrm{Na}_{2} \mathrm{O}$ depending on the raw materials used for cement production [11].

The mean alkali content of the concrete reported in 1990 was $7.4 \mathrm{~kg} / \mathrm{m}^{3} \mathrm{Na}_{2} \mathrm{O}$ equivalent. The spread of results was much less, ranging from 6.48 to $8.44 \mathrm{~kg} / \mathrm{m}^{3}$ which is more consistent and hence more reliable. Some aggregate may have released alkali into the concrete but it is not expected that this has occurred to the levels measured during this investigation.

BS 1881-124 states that the calculated value can be higher than the true alkali content of the cement used due to contributions from sources other than the cement such as the aggregate. Aggregates contain sodium and potassium compounds which are not readily available for reaction in concretes. The method of analysis given in BS 1881-124 could, however, extract the alkalis from a finely ground sample of such aggregate.

The results were not quantitatively considered in the assessment but qualitatively, showing that sufficient alkalis are present to enable ongoing alkali-silica reaction.

\subsection{Concrete expansion rate}

The rate of concrete expansion was determined in accordance with the British Cement Association (BCA) guidance [12] at core samples from Stage 1 and Stage 2 concrete. The samples were stored wet, in sealed polythene sleeves, over water, within individual containers at $38^{\circ} \mathrm{C}$. The expansion was measured weekly to 56 days and then every 28 days over a period of 12 months. The results are shown in Figure 4.

Four of the five core samples continued to expand over and above the initial expansion due to thermal and moisture effects indicating that the sample retrieved from Stage 1 concrete elements is not susceptible to ASR provided that alkalis are not released from the aggregate in excess of the ASR threshold. The expansion of the four Stage 2 core samples was found to be between $0.06 \%$ and $0.08 \%$ which corresponds to 600 to 800 microstrain. The BCA [12] states if the expansion is about 700 microstrain $(0.07 \%)$ or less, it is unlikely that there will be further expansion. Very reactive aggregate may however cause expansion rates up to 4000 microstrain $(0.4 \%)$.

The results indicate that expansion will be ongoing but at a slow rate of up to $0.22 \mathrm{~mm} / \mathrm{m}$ per year in unrestrained conditions. This is based on the linear expansion measured between Month 6 and 11. The results from Month 12 were discarded as it is apparent that drying of the samples took place. Furthermore, the petrographic analysis and the determination of the alkali content showed that ASR has not ceased and sufficient alkalis are available to prolong the reaction.

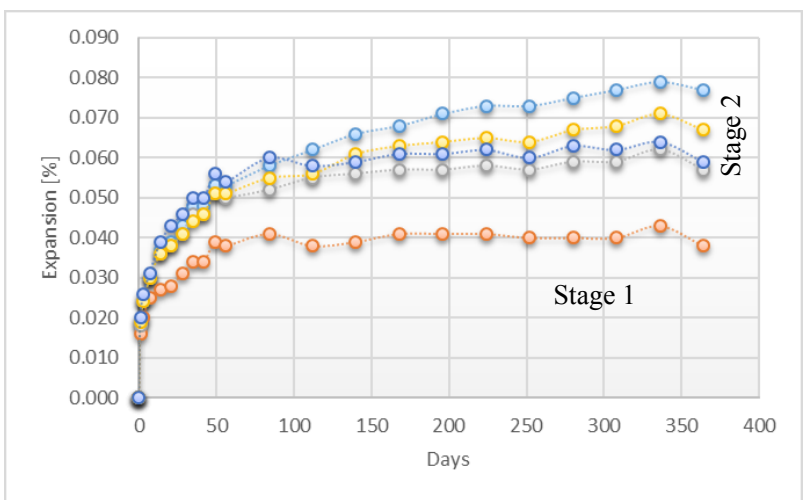

Fig. 4. Concrete core expansion

It is possible that the reaction may have slowed down over the past 25 years but no comparable tests were carried out in 1990 .

The results of the concrete testing, including the expansion rates, are summarised in Table 1.

\section{Effects on the powerhouse, 2015}

The effects of ASR on the structure were assessed by determining the displacement of the generator floor in vertical and horizontal directions, changes to the crane gauge and analysis of the load change in the anchors installed during the major refurbishment works from 1989-1991. Furthermore, monitoring data from angle brackets, fissurometer, triangular wall targets and extensometers were reviewed and analysed to incorporate into FEM model.

\subsection{Generator floor displacements}

The vertical and horizontal displacements were determined at generator floor level by measuring the distance between opposite columns of the structural frame between each unit and the level rise of the floor between the columns along 5 No. longitudinal grid lines. The structural frame comprises 22 No. pairs of columns (C1-C22) where only every second pair/line was fully accessible. Column pair/line No. $1(\mathrm{C} 1 / \mathrm{C} 2)$ is at the western end of the powerhouse where Unit \#1 is located.

The maximum horizontal column displacement was in the range of 129 to $131 \mathrm{~mm}$ between Units \#4 and \#7. The horizontal column displacement at generator floor level can be fully considered as downstream movement due to the restraint provided by the rock and intake dam. No displacement was found at column line No. 1 at the western side of Unit \#1. As reported by Mason and Molyneux [1] and in the 1990 inspection report [3] UK cement was used for both the structural frame and mass concrete elements of Unit \#1. The last pair of columns at the eastern end of the powerhouse is displaced by $72 \mathrm{~mm}$, see Figure 5. In 1990 the maximum displacement was measured to be $32 \mathrm{~mm}$ and predicted to be $62 \mathrm{~mm}$ in 2020 based on a linear expansion rate of $1 \mathrm{~mm} /$ year. 
Table 1. Summary of concrete test results

\begin{tabular}{|c|c|c|c|c|c|c|c|c|c|c|}
\hline Unit & $\begin{array}{l}\text { w/c- } \\
\text { ratio }\end{array}$ & $\begin{array}{l}\text { Cement } \\
\text { content }\end{array}$ & $\begin{array}{l}\text { Relative } \\
\text { severity } \\
\text { of ASR }\end{array}$ & $\begin{array}{l}\text { In-situ cube } \\
\text { compressive } \\
\text { strength } \\
{\left[\mathbf{N} / \mathbf{m m}^{2}\right]}\end{array}$ & $\begin{array}{l}\begin{array}{l}\text { E- } \\
\text { Modulus }\end{array} \\
{\left[\mathbf{N} / \mathbf{m m}^{2}\right]}\end{array}$ & $\begin{array}{l}\begin{array}{l}\mathrm{Na}_{2} \mathrm{O} \\
\text { (concrete) }\end{array} \\
{[\%]}\end{array}$ & $\begin{array}{l}\begin{array}{l}\mathrm{K}_{2} \mathrm{O} \\
\text { (concrete) }\end{array} \\
{[\%]}\end{array}$ & $\begin{array}{l}\begin{array}{l}\mathrm{Na}_{2} \mathrm{O} \text { Eq } \\
\text { (cement) }\end{array} \\
{[\%]}\end{array}$ & $\begin{array}{l}\begin{array}{l}\mathrm{Na}_{2} \mathrm{O} \text { Eq } \\
\text { (concrete) }\end{array} \\
{\left[\mathrm{kg} / \mathbf{m}^{3}\right]}\end{array}$ & $\begin{array}{l}\begin{array}{l}\text { Rate of } \\
\text { expansion }\end{array} \\
{[\mathrm{mm} / \mathrm{m} / \mathrm{year}]}\end{array}$ \\
\hline 5 & $0.5-0.6$ & 335 & High & 23.5 & 13,000 & 0.41 & 1.03 & 7.2 & 27.8 & 0.11 \\
\hline 5 & & & & & 10,500 & 0.19 & 0.42 & 3.1 & 11.9 & 0.015 \\
\hline 8 & $\begin{array}{l}0.45- \\
0.55\end{array}$ & 407 & Moderate & 33.0 & & 0.27 & 0.60 & 4.4 & 17.0 & 0.07 \\
\hline 8 & $\begin{array}{l}0.45- \\
0.55\end{array}$ & 368 & Moderate & 30.5 & 15,000 & 0.27 & 1.26 & 7.3 & 28.1 & 0.22 \\
\hline 8 & & & & 54.5 & 21,500 & 0.27 & 0.40 & 3.5 & 13.6 & \\
\hline 10 & & & & 38.0 & 13,000 & 0.29 & 0.50 & 4.1 & 15.8 & 0.15 \\
\hline
\end{tabular}

A displacement assessment was carried out in 2013 using FEM model [13] which was based on the 1990 site measurements. The theoretical maximum displacement expected in 2013 was $130 \mathrm{~mm}$ at Unit \#8 which generally agrees with the displacement measured in 2015.

The horizontal downstream displacement is not, however, the actual concrete expansion due to ASR. The downstream displacement at the generator floor is a magnified figure due to the rotation of the reinforced concrete structural frame around the heavily reinforced connection of the reinforced concrete column at the draft tube. The structural frame comprises a reinforced concrete section and a concrete encased steel column section up to the roof truss. The connection between the reinforced concrete and encased steel column section is just below the generator floor in the upper gallery.

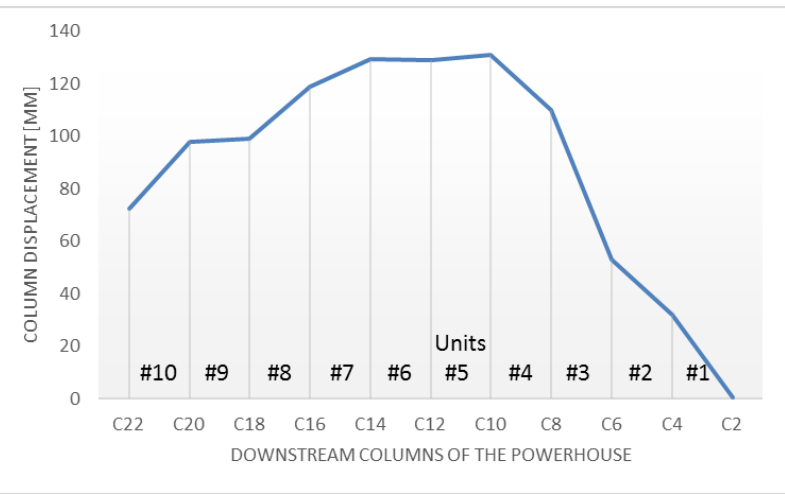

Fig. 5. Horizontal generator displacement

The vertical generator floor rise was determined along 5 No. longitudinal grid lines between the upstream and downstream columns and the maximum rise was found to be $97 \mathrm{~mm}$ along the centre line of the powerhouse on column grid line $\mathrm{C} 15 / 16$ (i.e. between Units \#7 and \#8) as shown in Figure 6. Longitudinal grid lines ' $A$ ' and ' $E$ ' are at the inner facing side of the upstream and downstream columns, respectively.

In 1990 the floor level rise was reported to be $76 \mathrm{~mm}$ and predicted to be $150 \mathrm{~mm}$ in 2020 . FEM modelling of the vertical displacement using the 1990 results expected a vertical rise of $135 \mathrm{~mm}$ in 2013 [13]. The expansion until 1990 indicated a vertical displacement of $3 \mathrm{~mm} /$ year whereas the rate decreased to $0.9 \mathrm{~mm} /$ year from 1990 to 2015 assuming linear progression.

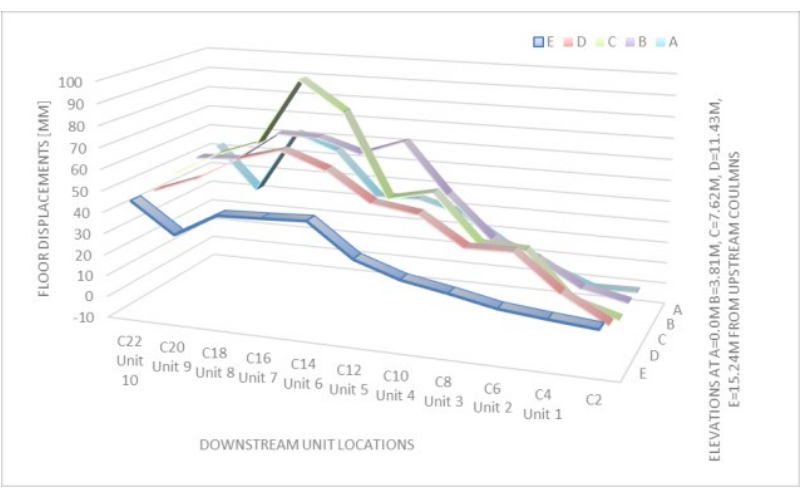

Fig. 6. Vertical generator floor level rise

\subsection{Crane gauge displacement}

The analysis of the crane gauge measurement data from 1960 to 2015 found the highest offset of $52 \mathrm{~mm}$ at Unit \#8 for a horizontal generator floor displacement of $109 \mathrm{~mm}$. This indicates an approximate displacement rate of $1 \mathrm{~mm} /$ year since construction. The displacement between Units \#4 and \#5 was found to be $40 \mathrm{~mm}$, which corresponds to the maximum horizontal generator floor displacement of $131 \mathrm{~mm}$.

Note that the above calculations considered a dormant deterioration period of 5 years from commissioning where structural effects due to ASR were not visible. The first evidence of deterioration was identified through the presence of hairline cracking in 1964.

The predictions from 1990 indicated a maximum crane gauge displacement of $72 \mathrm{~mm}$ (net) in 2020, comprising an upstream deflection of $13.7 \mathrm{~mm}$ and a downstream deflection of $85.8 \mathrm{~mm}$ [3].

\subsection{Effects of load anchors}

The 1984/85 investigations concluded that the root cause of the deterioration was the instability of the spirals and it was recommended to install post-tensioned anchors as 
mitigation measure. Two types of anchors, comprising vertical concrete anchors and inclined rock anchors, were installed around each generator unit during the powerhouse refurbishment works from 1989 to 1991. The total number of anchors is 115 No. and load cells were added for monitoring at 6 No. selected anchors at Units \#7, \#8 and \#9 in 1995 [2].

The anchors were designed with a safe working load of $1962 \mathrm{kN}$ and an ultimate breaking load capacity of $2894 \mathrm{kN}$ [2]. From installation of the load cells in 1995 to date the load has linearly increased at the 6 No. anchors with rates ranging from 10 to $17 \mathrm{kN} /$ year. This has affected the designed safe working load of the anchors but also had positive effects on the vertical displacement of the generator floor.

The reduced rate of vertical displacement indicates that the anchors provide a certain degree of restraint. This appears to have a positive effect on the vertical expansion of the affected mass concrete. The vertical expansion has decreased from $3 \mathrm{~mm} /$ year for the period until 1990 to less than $1 \mathrm{~mm} /$ year from 1990 to 2015. The number of anchors that are monitored is limited but the load cells represent the area of highest vertical expansion based on the level survey.

\subsection{Powerhouse failure mechanism}

The analysis of the instrumentation data and the horizontal and vertical generator floor displacement surveys were used to assess the potential failure mechanism of the powerhouse frame. The condition assessment confirmed that ASR is still ongoing, resulting in the development of a potential primary hinge at generator floor level at the connection between the reinforced concrete column (below generator floor) and the encased steel column (above) where cracking was identified during the inspection. A secondary potential hinge is likely to form in the region above the crane rail due to the change in section of the encased steel column and the restraint provided by the roof truss. No cracking was identified at that location. The main point of rotation is in the heavily reinforced area above the draft tubes where cracking was reported in 1990 [1, 3].

\section{Residual life}

The residual life of the structure was assessed by 3D FEM modelling of the powerhouse and intake structure using the data from the 1990 and 2015 inspections and the monitoring data from the instrumentation installed at the structures. The model showed that ASR was also required to take place at the intake dam as the movement observed to date could not solely have been caused by ASR in the Stage 2 mass concrete elements of the powerhouse. The presence of ongoing ASR in the intake dam was confirmed by petrographic analysis.

The FEM model showed that the current compressive stresses at the interface between intake and powerhouse are $25 \mathrm{~N} / \mathrm{mm}^{2}$ whereby the in-situ compressive strength was determined to range from 23.5 to $54.5 \mathrm{~N} / \mathrm{mm}^{2}$ with an average of $36 \mathrm{~N} / \mathrm{mm}^{2}$. Ongoing deterioration and associated expansion due to ASR in the intake may result in crushing of the concrete at the outlets.

The residual service life of the powerhouse structure excluding the structural frame and anchors, was predicted to be 30 years for Units \#1 to \#4 and approximately 10 years for Units $\# 5$ to $\# 10$, i.e. 2025 , using the FEM model. An analysis of the frame showed that the vertical elements are already overstressed in the areas of the largest displacement and collapse is likely to occur after 2035. The intake dam in its current state is likely to have a remaining service life of 20 years.

\section{Options to control the effects of ASR}

The protection of concrete elements against ongoing ASR is practically unrealistic but theoretically feasible provided the humidity in the concrete can be reduced to below $75-80 \% \mathrm{RH}$, the reaction is stopped by injecting lithium or carbon dioxide or all affected and susceptible concrete is replaced. In the case of the powerhouse and intake dam, options were identified to control the effects of ASR in order to extend the service life of the plant. In practice, these measures are to prevent significant misalignment of the turbines that could affect power generation and any health and safety issues to the personnel operating and maintaining the plant. Note that there has not been any reported case of turbine ceasing and health \& safety issues due to ASR. Measurements of the turbine blade tip clearances show that issues are not expected in the near future.

Options to control the effects of ASR were reviewed and assessed based on their advantages and disadvantages. The following options were identified based on the findings of the condition assessment, methods used at other hydropower plants [14] and theoretical solutions to control ASR in concrete.

- Do nothing - health and safety control options:

- Aesthetic repairs such as crack repair by grouting or injection and other maintenance under the current O\&M requirements;

- Structural modifications to control/manage ASR expansion:

- Slot-cutting to accommodate expansion;

- Installation of post-tensioned anchors to restrain the expansion;

- Partial or full replacement of affected mass concrete;

- Structural modifications to address the integrity of the structural frame:

- Installation of post-tensioned anchors to reduce the rate of horizontal displacement;

- Installation of replacement downstream columns;

- Strengthening of the downstream column in the region above the crane rail;

- Long-term reaction control to reduce ASR expansion:

- Protection against water ingress using membranes or coatings;

- Injection using lithium or carbon dioxide; 
- Electro-chemical techniques to reduce relative humidity in concrete.

The Do-Nothing option would only involve localised repairs to prevent any health and safety issues to the operating and maintenance personnel due to falling spalled concrete and trip hazards. It assumes that the plant would be decommissioned within the near future.

ASR can be controlled/managed by preventing the concrete to expand and/or by allowing the concrete to expand in a defined direction that does not affect the integrity of the structural frame and causes operational issues due to machinery misalignment. The posttensioning anchors installed at the powerhouse from 1989 to 1991 showed that vertical displacement can be limited and therefore, additional anchors could further reduce concrete expansion and movement which would conform with the recommendations of IStructE Report 62 of limited strengthening [7]. This however increases the stresses in the concrete and, due to the continuously deteriorating E-Modulus of the affected concrete, it would be required to allow the concrete to expand in a defined direction. This could be achieved by cutting slots between the units. Slot-cutting through the "penstocks" and installing a flexible joint would also control the thrust from the intake dam. Slot-cutting is likely required regularly to compensate for the closure of the slots. Partial or full replacement of the affected mass concrete would be the best option to mitigate ASR but is currently economically and operationally not viable.

Due to the development of hinges in the structural frame, strengthening and replacement options were considered. The columns can be strengthened and the downstream generator floor movement can be limited by installing horizontal anchors. This however requires the provision for the concrete to expand in a defined direction and therefore, slot-cutting would also be required for this modification.

ASR can be theoretically controlled, i.e. the reaction can be stopped, by reducing the relative humidity in the concrete to less than $75-80 \%$ or by using chemicals. The relative humidity in a mass concrete structure exposed to water is unlikely to be achieved within a defined time by natural drying. The relative humidity could be reduced by electro-chemical techniques, but this would involve long-term research and testing prior to application on such a structure. In addition to the water movement, the elements would require waterproofing to prevent continuous water ingress. The use of chemicals, such as lithium or carbon dioxide, works in a small scale and only in the surface-near zone. The injection of such gases in fragile concrete is also not desirable.

The options most applicable for Nalubaale are considered to be restraining the vertical and downstream movement by post-tensioning anchors, allowing the concrete to expand between the units and reducing the thrust from the intake dam by repeated slot-cutting and strengthening the powerhouse frame. This comprehensive rehabilitation strategy could potentially extend the service life of the power plant until 2045.

\section{Summary}

ASR is still ongoing at the hydropower station but at a relatively low rate of $0.22 \mathrm{~mm} / \mathrm{m}$ per year in unrestrained conditions. The petrographic examination confirmed that it is unlikely that the reaction will slow down in the near future.

The cause of the ASR is the reactive coarse aggregate which was identified to be greenschist. The concrete compressive strength does not appear to have reduced since 1990 but the E-Modulus was found to have linearly decreased to about $1 / 3$ of its expected original value.

The rate of the horizontal displacement of the generator floor was found as previously predicted with a rate of $2.3 \mathrm{~mm} /$ year. However, the rate of the vertical displacement has reduced from $3 \mathrm{~mm} /$ year to $0.9 \mathrm{~mm} /$ year since the installation of the post-tensioning anchors in 1989-1991, indicating that the anchors have been beneficial in controlling the expansion.

This observation has been considered during the assessment of potential remediation strategies to control and manage ASR in the structure to extend the service life of the plant. The installation of further anchors, (vertical, inclined and horizontal) can control the expansion in vertical and horizontal downstream directions. It would however be necessary to allow the ASR to expand in a defined direction between the units where slot-cutting will need to be carried out.

The detailed design of any rehabilitation methods will need to take into account the additional stresses from the post-tensioning in a continuously deteriorating concrete, particularly the linearly decreasing E-Modulus.

The service life of the structure, excluding the anchors, could be increased from currently remaining 10 years up to potentially 25 to 30 years.

The authors would like to thank UEGCL as owner of the power station for the various discussions from inception until completion of the assessment. The team of ESKOM Uganda is thanked for providing valuable historic information, the instrumentation data, very fruitful discussions and support during the project. Professor Pilate Moyo is hugely thanked for his contributions and input during the project and in particular in implementing the FEM model.

\section{References}

1. P.J. Mason, J.D. Molyneux, Proc. of ICE, Water, Maritime \& Energy, 1998, pp.226-237

2. E. Arcangeli, C. Stella, Water Power \& Dam Constr., 1993, pp.23-30

3. Sir Alexander Gibb \& Partners Ltd., "Report on additional studies into power station cracking”, March 1991

4. I. Sims, A.B. Poole, CRC Press, 2017

5. D. Stark, CANMET/ACI $2^{\text {nd }}$ Int. Conf. On Durability of Concrete, SP-126, ACI, 1991, pp.973-987

6. J. Stark, Schriftenreihe des F.A. Finger-Instituts fuer Baustoffkunde, Bauhaus Universitaet Weimar, 2008

7. IStructE, Report 62, 1992, Addendum 2010

8. Applied Petrography Group, APG Special Report 2, 2010 
9. J. Stark, B. Wicht, Birkaeuser Verlag, Basel, Switzerland, 2001

10. The Concrete Society UK, http://www.concrete.org.uk/fingertipsnuggets.asp $? \mathrm{cmd}=$ display\&id=525, accessed 28 Feb 2018

11. A.M. Neville, Pearson Education Ltd., UK, 1995

12. British Cement Association, Report of Working Party' 1992

13. Hatch, "Grow3D FEA of Nalubaale Power Station Nalubaale ASR Investigations Phase 2", April 2013

14. D.D. Curtis, Proc. of $11^{\text {th }}$ ICAAR, Quebec, Canada, 2000 